\title{
MODELING AND MIP-HEURISTICS FOR THE GENERAL LOTSIZING AND SCHEDULING PROBLEM WITH PROCESS CONFIGURATION SELECTION
}

\author{
Beatriz Empke Villas Boas ${ }^{1}$, Victor C. B. Camargo ${ }^{2 *}$ and Reinaldo Morabito ${ }^{3}$
}

Received June 16, 2020 / Accepted March 10, 2021

\begin{abstract}
In some industrial contexts, such as in the molded pulp, paper, furniture and electrofused grain industries, items or final products are obtained by processes that can produce several types of products simultaneously. These processes are considered here as any specific mode of operation or configuration of a production system that can produce several different items simultaneously and in varied quantities. The production planning and scheduling in these industrial contexts involve decisions of: i) configuration selection of these processes; ii) production lot sizing of selected configurations; and iii) decisions of scheduling these selected configurations. In this work, a mixed integer programming model (MIP) is presented to adequately represent this integrated problem, called the general lotsizing and scheduling problem with process configuration selection. In order to achieve effective production plans at acceptable computational times in practice, Relax-and-Fix and Fix-and-Optimize heuristics based on this model are also presented. Computational experiments were performed solving the model with an optimization solver and applying the proposed heuristics in examples inspired in molded pulp, furniture and electrofused grain packaging companies. The results show that MIP-heuristics can solve the problem more effectively (good quality solution in acceptable time) than simply using the solver for the mathematical model.
\end{abstract}

Keywords: Lot sizing and scheduling, process configuration selection, mixed integer programming, MIPheuristics.

\section{INTRODUCTION}

The short-term production planning problem for intermittent processes, in general, is a lotsizing and scheduling problem. Lot sizing involves decisions of how much to produce to meet the demand of the final products, respecting the production capacities and considering the costs

\footnotetext{
*Corresponding author

1 Departamento de Engenharia de Produção, Universidade Federal de São Carlos (UFSCar), São Carlos, SP 13565-905, Brazil, E-mail: beatrizempke@gmail.com - https://orcid.org/0000-0003-2839-944X

2 Departamento de Engenharia de Produção, Universidade Federal de São Carlos (UFSCar), São Carlos, SP 13565-905, Brazil, E-mail: victor.camargo@dep.ufscar.br - https://orcid.org/0000-0001-9332-3025

3 Departamento de Engenharia de Produção, Universidade Federal de São Carlos (UFSCar), São Carlos, SP 13565-905, Brazil, E-mail: morabito@ufscar.br - https://orcid.org/0000-0002-3948-305X
} 
involved. When the change of production from one product to another consumes resources (time, material, labor) and generates costs dependent on the production sequence of the lots, the scheduling decisions of the lots become more important. As resource consumption influences lot sizing, it is increasingly common to integrate these decisions into decision making (Clark et al., 2011). In some literature reviews, such as in Drexl \& Kimms (1997), Jans \& Degraeve (2008) and Copil et al. (2017), the integration of lotsizing problems and scheduling can be observed.

In several industrial contexts, such as the chemical, oil, paper and cardboard, furniture, molded pulp, electrofused grains, wood and foundry industries, among others, products demanded are, in general, manufactured using production processes that produce several products simultaneously (Johnson \& Montgomery, 1974). These processes are considered here as any specific mode of operation or configuration of a production system that can produce several different items simultaneously and in varied quantities. For example, in a furniture company, a sheet of wood can be cut in several ways, i.e., there are several possible cutting patterns to cut the sheets and to obtain a set of items from each pattern. A cutting pattern can be configured in cutting equipment to obtain a single type of item in several quantities, or several types of items in different quantities of each type. In the latter case, each cutting pattern is configured as a simultaneous production process of several types of items. To produce all the items demanded in a planning horizon, a combination of process configurations (cutting patterns) must be selected to cut the sheets (Melega et al., 2018).

In another example, in an electrofused grain company, the raw material (quartz and petroleum coke, for example) is transformed into grains through a series of industrial processes. These grain are classified according to their size by a set of different vibrating sieves, which together separate the grains into different granulometric ranges. That is, each set of sieves allows the simultaneous production of several grain sizes and in different quantities of each size, similar to the example of the cutting pattern in the furniture company. To produce the grains in the required sizes and quantities, various process configurations (i.e., various combinations of different vibrating sieves) must be selected for use (Luche et al., 2009).

Selecting the configuration and scheduling of these configurations can influence planning and production control decisions, that is, the quantity and variety of products produced, the consumption of resources and the use of capacities. The problem of this production planning can be called a general lotsizing and scheduling problem with process configuration selection. Note that this problem involves configuration selection decisions of these processes, production lotsizing decisions of the selected configurations and scheduling decisions of these configurations. Each production lot contains several types of products being produced simultaneously. It should be noted that this problem is different from the general problem of lot sizing and scheduling, where each lot contains only one type of product.

Several examples of industries that use processes with simultaneous production of different products have already been studied in the literature. However, these papers are applied to specific cases of these industries, considering the particularities of their production processes and other specificities of their planning environments. In general, the solution methods are also customized 
and specific to the cases studied and difficult to adapt to the cases of other industries, whether specialist or mathematical programming heuristics. Therefore, the objective of this study is to present a mathematical modelling and solution methods for the general lotsizing and scheduling problem with process configuration selection. To the best of our knowledge, there are few studies addressing this problem in the literature in contrast to the traditional lotsizing and scheduling problem, which has been extensively studied.

The main contributions of this paper are: (i) the presentation of an integer mixed programming model (MIP) that includes the objectives and constraints of the problem integrated with process configuration selection. The model must consider inventory balancing constraints to meet demands, capacity constraints and identification of changes in production process configurations. These process configuration changes result in times and costs dependent on the production sequence of the configurations. The proposed model represents the decision making for this type of problem and presents the traditional constraints adapted from the lotsizing and scheduling problem, besides the process configuration selection decisions. The objective function aims to minimize inventory costs, delay and change of production process settings. (ii) The proposal of a set of heuristics based on mathematical programming as the solution method for the model. These heuristics can be easily adapted when additional specificities need to be considered in the problem and incorporated into the mathematical model. Several solving strategies are investigated that comprise constructive and improvement heuristics, specifically the MIP-heuristics Relax-and-Fix and Fix-and-Optimize.

In Section 2, we discuss how a process and its configurations compose the industrial environment of a process industry. The lotsizing and scheduling problem with process configuration selection is defined in Section 3 and a general mathematical model is proposed. MIP-heuristic solution methods are proposed for the problem in Section 4. The results of the computational tests, with examples inspired by molded pulp packaging, furniture and electrofused grain companies, are presented in Section 5. Finally, the conclusions and future directions of the research are presented in Section 6.

\section{LOTSIZING AND SCHEDULING PROBLEM WITH PROCESS CONFIGURATION SELECTION}

Process industries are those that add value to materials by mixing, separating, forming or chemical reactions (Kopanos \& Puigjaner, 2019). Processes can be continuous or batch-based and generally require strict process control and high investments. Fransoo \& Rutten (1994) classify process industries as presented in Table 1 . The production flow differentiates between batch production and continuous production. Process industries that produce in batches have a large set of types of items produced in small quantities. On the other hand, continuous production flow presents a low variety of items produced in large volumes. The difference between the items is small since the processing of the items follows very similar production routings and, in general, the value added in the item is low. 
Table 1 - Typology for Process Industries. Fransoo \& Rutten (1994).

\begin{tabular}{|c|c|c|c|c|c|c|}
\hline Batch/ & & & & & $\rightarrow$ & Process/flow \\
\hline Drugs & $\begin{array}{l}\text { Speciality } \\
\text { chemicals }\end{array}$ & Rubber & $\begin{array}{c}\text { Major } \\
\text { chemicals }\end{array}$ & Paper & Brewers & Steel Oil \\
\hline
\end{tabular}

In these industries, the same process can produce more than one type of product and one type of product can be produced by several alternative process configurations. Figures 1, 2 and 3 show examples of this feature in process industries. Figure 1 presents an example of a process used in the molded pulp packaging industry. This type of industry uses a set of molds to produce packaging for eggs and fruits, made from pulp produced from recyclable paper. In this example, the selected process configuration can produce 3 different types of products at each mold stamping: two packs for 12 eggs, one pack for 24 eggs and two packs for 4 fruits. Other mold configurations can be used to produce different types of products and/or in other quantities. An alternative configuration could produce only 2 different types of products at each stamping: three packs for 12 eggs and four packs for 4 fruits. Having different possible configurations, the sequence of the configurations and the time of use of each one should be defined.

Figure 1 - Example of a production process configuration in a molded pulp packaging industry.

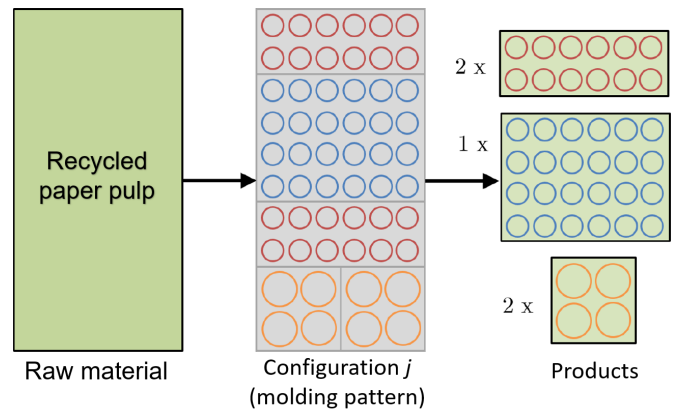

Figure 2 - Example of a production process configuration in a furniture industry.

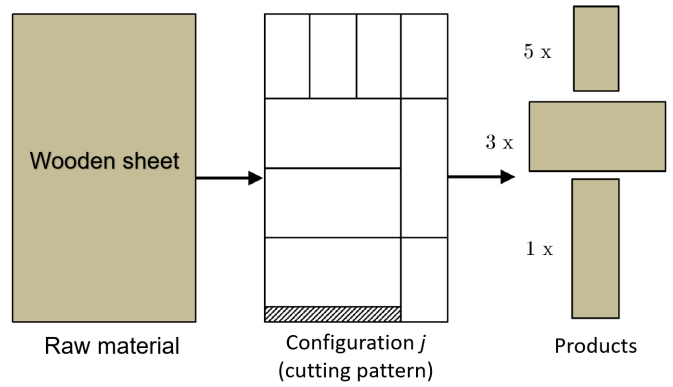


Figure 3 - Example of a production process configuration in a paper industry.

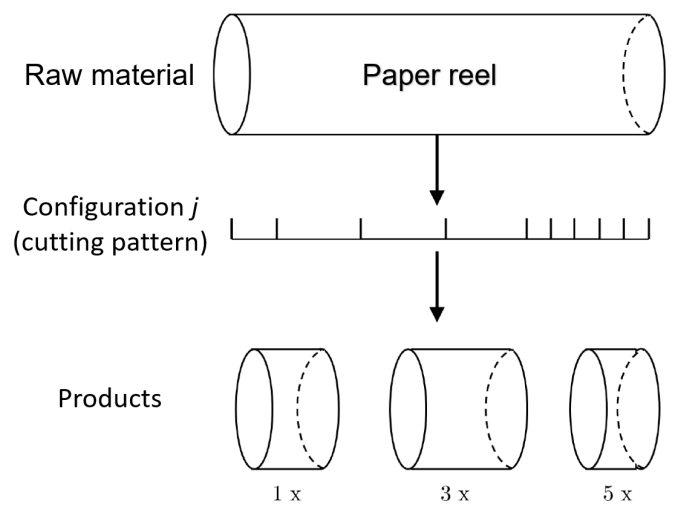

Figures 2 and 3 show the case where the process configuration is a cutting pattern that cuts larger units (raw material) into smaller units ordered by customers. Figure 2 depicts the case of a furniture industry, where a sheet of wood (or a pack of sheets) is cut according to a twodimensional cutting pattern for the production of items used in furniture assembly. Note that in this process three types of items are produced in different quantities. Figure 3 shows a onedimensional cutting pattern (configuration) in a paper industry, where a large reel of paper is cut into smaller-sized reels to obtain different products.

Note that, in each case, there may be many possible process configurations to be used, and the process configuration selection decision must be integrated with the remaining production planning decisions. Unlike the flexibility problem of Fiorotto et al. (2018), which studies different known paths in the production process among the available machines, our proposal addresses the different configurations of a process (mixing, separation, conformation or chemical reactions) that are known a priori.

The flexibility of the selection of these configurations and the integration with lotsizing and scheduling decisions can allow important reductions in inventory and waste of materials.

\subsection{Lot sizing and scheduling}

The lotsizing and scheduling problem has been presented in the literature in different types of industries, such as beverages (Toscano et al., 2019, 2020), foundries (Furtado et al., 2019; de Araujo et al., 2008), textile (Camargo et al., 2014), glass packaging (Fachini et al., 2018), animal nutrition (Clark et al., 2010), poultry (Boonmee \& Sethanan, 2016), paper (Leao et al., 2017), pulp (Furlan et al., 2015), food (Claassen et al., 2016), among others. The complexity of these problems is influenced by the characteristics of the production system, such as time horizon, number of levels in product production, number of products, capacity and resource constraints, damage to items in inventory, demand, presence of exchanges, lack of products, among others (Karimi et al., 2003). 
In the manufacturing of some products such as feed, soft drinks, beer, foundry among others, the production sequence influences their costs and production times (Ferreira et al., 2012; Toledo et al., 2009). This problem can be solved in two phases: in the first, the quantity to be produced is defined, considering demand, production capacity and inventories (lotsizing problem). In the second phase, the sequence of this production is defined, considering the times and costs of production changeovers between products. In this case, the changeover times and costs depend on the defined sequence of production of the lots. For a better solution approach, several authors (see Drexl \& Kimms (1997) and Copil et al. (2017)) present models considering the integrated problem of lot sizing and scheduling, which define what to produce, lot quantities and the sequence of the lots. In general, each lot refers to the quantity produced of a single type of product at a time.

The lotsizing and scheduling problem can be represented by several different mathematical models, depending on the characteristics of the problem, as can be seen in Drexl \& Kimms (1997). Among the models, the General Lotsizing and Scheduling Problem (GLSP) is a mathematical model that integrates the lot sizing and scheduling of several products in a single machine, subject to capacity constraints (Karimi et al., 2003). According to Almada-Lobo et al. (2015), the GLSP, together with CLSD (Capacitated Lotsizing Problem with sequence-dependent setups), are the most studied models in the literature. Fleischmann \& Meyr (1997) present GLSP considering a planning horizon of $|T|$ periods, which are divided into a set of $\left|S_{t}\right|$ sub-periods. A single item is produced by sub-periods, therefore it is easy to differentiate the production sequence. This model has been used in several papers for this facility (for example: Ferreira et al. (2008), Toso et al. (2009), Martínez et al. (2016) and others).

\subsection{Process configuration selection}

Lotsizing and scheduling models used for industries with discrete production can be adapted to process industries to address the production specificity following alternative process configurations. Some authors have already studied some formulations and methods of resolution for the lotsizing and scheduling problem with process configuration selection for different industries. Sahinidis \& Grossmann (1992) present a model for lot sizing and scheduling and process configuration selection for the chemical industry. Lu \& Qi (2011) presented models for the chemical and poultry industries and proposed heuristics. Gaudreault et al. (2011) proposed two mathematical models for the problem of process configuration selection and its sequencing in the wood industry, the first based on mixed integer programming and the second on constraint programming.

In oil refineries (Shi et al., 2014; Persson et al., 2004; Göthe-Lundgren et al., 2002), production decisions involve selecting process configurations for each production unit over the planning horizon to determine the quantities of diesel, gasoline and other types of products that depend on the process configurations. Chunpeng \& Gang (2009) proposed two strategies to integrate production planning and process configuration scheduling in refineries, the first uses a rolling horizon and the second uses a two-stage decomposition. In the electrofused grain industry, the 
size of the manufactured grain depends on the set of sieves used. Luche \& Morabito (2005) proposed a mathematical model that consists of a combination of the problem of process configuration selection and the lot sizing problem. A constructive heuristic was also proposed as a solution method for this problem in Luche et al. (2009).

Martínez et al. (2016) and Martínez et al. (2018) studied a molded pulp packaging industry and proposed models aimed at reducing setup and inventory costs. Due to the large number of existing molding patterns, which are difficult to enumerate in advance, the selection of the process configuration is also a model decision. Martínez et al. (2019) proposed solution methods to solve the models based on Branch-and-Check. In the furniture, paper and steel industries this integration also occurs regarding lot sizing, scheduling and process configuration selection with the generation of configurations. In these cases, items are obtained by cutting larger objects following a cutting pattern. Each cutting pattern is a process configuration and is usually done by solving several cutting and packaging problems. These studies can be found in Gramani et al. (2009) and Alem \& Morabito (2013) for the furniture industry, in Poltroniere et al. (2008) for the paper industry and in Nonås \& Thorstenson (2008) for the steel industry. The proposed solution methods are Lagrangean heuristics, column generation methods and specialist heuristics for subproblems.

\subsection{Research proposal}

In this paper, the mathematical model proposed for the general lotsizing and scheduling problem with process configuration selection is in line with the basis of the models presented in the literature. The GLSP is adapted to include process configuration selection decisions and, thus, several products can be produced per subperiod. Each lot is related to the production time of a process according to the selected configuration (instead of the produced quantity of an item, as in GLSP). That is, the quantity of items is determined by the usage time of each of the configurations of the production process and the scheduling of configurations must be defined in the planning horizon. In this case, it can be stated that the set of configurations is known a priori.

The proposed solution methods for the problem are mathematical programming heuristics which are generally easy to adapt to possible changes in the mathematical model. In the literature, although some heuristics of the Relax-and-Fix and Fix-and-Optimize types can be found, most of the solution methods are specific to the problem of each industry addressed. Therefore, we propose a set of constructive and improvement heuristics combinations based on mathematical programming.

\section{PROBLEM DEFINITION}

The lotsizing and scheduling problem with process configuration selection aims to determine the quantity of items to be produced during a planning horizon to meet a known demand. The production of the items occurs by processes, therefore it is necessary to select the configuration of production processes that will be used. It is worth mentioning that all possible configurations 
are known a priori. The case of generating new configurations is not dealt with in this paper and depends largely on specific characteristics of the production process involved. For example, generating process configurations in molded pulp packaging industries involves several specificities of the equipment and is not a simple task, as discussed in Martínez et al. (2016, 2018). The planning horizon comprises $|T|$ time periods, which are divided into $\left|S_{t}\right|$ subperiods. In each subperiod, only one configuration of the production process can be used, but several types of items can be produced. In the case of changeover between two different production process configurations during the planning horizon, there is production time consumption and the changeover also incurs costs dependent on the production sequence. The total time consumed in a period, which includes the setup times of the machines and the production of the items, is limited to the time available in the period.

The production plan must consider that inventories and backlogs are allowed but they incur costs. Consequently, a production plan with minimum costs of inventory and backlogging of items and setup of production processes is desired. By considering the characteristics of the problem, the GLSP (General Lotsizing and Sequencing Problem) with some adaptations can represent the problem described. After presenting the model, some considerations are made about the differences from the classic GLSP model.

Consider the following indexes, parameters and decision variables:

\begin{tabular}{|l|l|}
\hline \multicolumn{2}{|l|}{ Indexes } \\
\hline$i \in N$ & products; \\
$j, k \in K$ & process configurations; \\
$t \in T$ & periods; \\
$s \in S_{t}$ & subperiods; \\
$F_{t}$ & first sub-period of the period $t$ \\
$L_{t}$ & last sub-period of the period $t$ \\
\hline
\end{tabular}

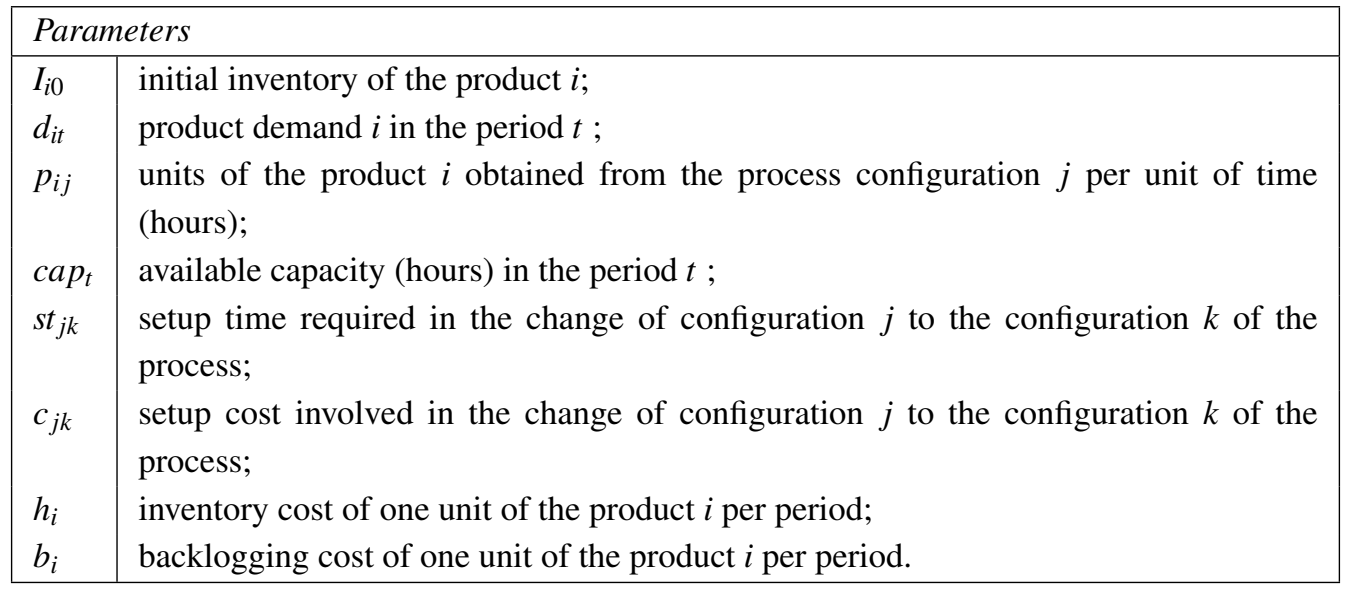




\begin{tabular}{|l|l|}
\hline \multicolumn{2}{|l|}{ Variables } \\
\hline$X_{j s}$ & process usage time in configuration $j$ in subperiod $s ;$ \\
$I_{i t}$ & inventory of product $i$ at end of period $t$ \\
$B_{i t}$ & backlog of product $i$ at the end of the period $t ;$ \\
$Y_{j s}$ & 1, if the machine is prepared for the configuration $j$ in the subperiod $s ; 0$, otherwise; \\
$Z_{j k s}$ & 1, if a changeover from the configuration $j$ to the configuration $k$ occurs in the \\
& subperiod $s ; 0$, otherwise. \\
\hline
\end{tabular}

$$
\text { Minimize } \sum_{i \in N} \sum_{t \in T}\left(h_{i} I_{i t}+b_{i} B_{i t}\right)+\sum_{j, k \in K} \sum_{s \in S} c_{j k} Z_{j k s}
$$

\section{Subject to}

$$
\begin{array}{lr}
I_{i(t-1)}-B_{i(t-1)}+\sum_{j \in K} \sum_{s \in S_{t}} p_{i j} X_{j s}=d_{i t}+I_{i t}-B_{i t}, & \forall i, t \\
\sum_{j \in K} \sum_{s \in S_{t}} X_{j s}+\sum_{j, k \in K} \sum_{s \in S_{t}} s t_{j k} Z_{j k s} \leq c a p_{t}, & \forall t \\
X_{j s} \leq \operatorname{cap}_{t} Y_{j s}, & \forall j, t, s \\
\sum_{j \in K} Y_{j s}=1, & \forall t, s \in S_{t} \\
Y_{j L_{(t-1)}}=\sum_{k \in K} Z_{j k F_{t}}, & \forall j, t \\
Y_{j(s-1)}=\sum_{k \in K} Z_{j k s}, & \forall j, t, s \in S_{t} \backslash F_{t} \\
Y_{k s}=\sum_{j \in K} Z_{j k s}, & \forall k, t, s \in S_{t} \\
Y_{j s} \in\{0,1\}, X_{j s} \geq 0 & \forall j, t, s \in S_{t} \\
I_{i t}, B_{i t} \geq 0 & \forall i, t \\
Z_{j k s} \geq 0 & \forall j, k, t, s \in S_{t}
\end{array}
$$

The objective function (1) aims to minimize the costs of inventory, backlogging and change of production process configurations. Constraints (2) define the inventory balance for each product $i$ in each period $t$. Constraints (3) ensure that process usage time and machine setup time are limited by capacity in each period $t$. In case of production using configuration $j$ in subperiod $s$, the constraints (4) impose that the machine must be prepared for this process configuration in this subperiod. Constraints (5) impose that the machine is prepared for one configuration in each subperiod of the planning horizon. Constraints (6) - (8) are replacements for constraints $\left(Z_{j k s} \geq\right.$ $\left.Y_{j(s-1)}+Y_{k s}-1, \forall j, k, s\right)$ and define $Z_{j k s}$, i.e. when there is a change of process configurations on the machine (for more details on the disaggregated form of these constraints, see Wolsey (1997)). Constraints (6) relate the configuration $j$ prepared in the last sub-period of the period $t-1\left(L_{t-1}\right)$ to a change identified at the beginning of period $t$ (sub-period $F_{t}$ ). Constraints $(7)$ relate con- 
figuration $j$ prepared in subperiod $s-1$ to an identified change in the next subperiod $s$. Finally, constraints (8) define that if configuration $k$ is prepared in subperiod $s$, there is a process change in that subperiod. Note that variables $Z_{j k s}$ can assume values 1 when $j=k$. In this case, it is enough to have the costs $c_{j k}$ properly parameterized. The decision variable domains are described in constraints (9) and (11).

By simplicity and without loss of generality, the costs are considered period independent. If the characteristic of the problem requires that the costs be different from period to period, cost parameters such as $h_{i t}, b_{i t}$ and $c_{j k t}$ and changes according to the objective function can be considered.

As can be seen, variables $I$ and $B$ are interpreted identically to the classic GLSP model. However, variables $X, Y$ and $Z$ in the classic GLSP represent respectively: the lot sizes of the products, the setup to produce the products and, the changeover of setups for the products in the machines. In the extension proposed in this paper, variables $X, Y$ and $Z$ represent respectively: the usage time of a specific process configuration, the setup for a specific configuration, the changeover of setups between two different configurations. The demand balance constraints are also modified, where the lotsizing variables $X$ are multiplied by a factor which represents the number of units of each product obtained by each process per time unit.

\section{MIP-HEURISTICS}

A heuristic is a set of steps that aims to achieve a good quality solution in a short computational time. Karimi et al. (2003) divide heuristics for lotsizing problems into two categories: specialized heuristics and heuristics based on mathematical programming.

Despite the similarity of the lotsizing and scheduling problem and the problem addressed in this paper, the specialized heuristics are not easily adapted to the case that includes the process configuration selection. When adapting, the configuration that produces the demanded products must be selected. In order to avoid an accumulation of stocks, the configuration should not produce large quantities of non-demanded items. In addition, the configuration considering the changeover times and costs between these two configurations used must be selected.

\subsection{Heuristics based on mathematical programming}

Heuristics based on mathematical programming, or hybrid heuristics, combine heuristics with exact mathematical programming methods. These heuristics usually provide good solutions to the lotsizing and scheduling problem, they are more general and can be easily adapted to different problems. However, in general they are more difficult to implement than specialized heuristics due to the necessary technical concepts and have a higher computational complexity for real problems (Maes \& Wassenhove, 1988; Karimi et al., 2003). According to Pochet \& Wolsey (2006), this method consists of modifying the mixed integer programming (MIP) through relaxation of constraints, relaxation of integrality or fixing some variables. By understanding the use of the MIP, these heuristics are also called MIP-heuristics. Within this category of heuristics, the 
most common for the lotsizing and scheduling problems are the Relax-and-Fix and the Fix-andOptimize heuristics. They are explored as solution methods for the present general lotsizing and scheduling problem with process configuration selection.

\subsubsection{Relax-and-Fix}

This is a constructive heuristic based on exact mathematical programming methods that was proposed by Dillenberger et al. (1994). The integer variables are partitioned into $P$ sets, where $Q_{p}$ is the set of variables of the partition $p$, and $p=1,2, \ldots, P$. The size of $P$ defines the number of iterations of the heuristics. In our case, the variables can be split by period, i.e., $P=|T|$. For the iteration $p=1$, the decision variables of sets $Q_{1}$ (from the first period) are defined as integer and the remaining variables are relaxed, creating the $M I P^{1}$ problem. The integer values found for $Y_{j s} \mid s \in Q_{1}$ (all the variables of the sub-periods that compose the first period) of the best feasible solution in the iteration $p=1$ are fixed in the following iterations. The integer values found for $Y_{j s}$ in previous iterations are defined as $\bar{Y}_{j s}$. Subsequently, for the remaining sets $p, 2 \leq p \leq P$, the $M I P^{p}$ contains the variables $\left(Y_{j s} \mid s \in Q_{1} \cup Q_{p-1}\right)$ fixed at the values of $\bar{Y}_{j s}$ found in the previous problem $\left(M I P^{p-1}\right)$. The variables in the set $Q_{p}$ are defined as integers, as shown in the following model.

$$
\left(M I P^{p}\right) \quad \text { Minimize } \sum_{i \in N} \sum_{t \in T}\left(h_{i} I_{i t}+b_{i} B_{i t}\right)+\sum_{j, k \in K} \sum_{s \in S} c_{j k} Z_{j k s}
$$

\section{Subject to}

$$
\begin{array}{lr}
(2)-(8) & \\
X_{j s} \geq 0 & \forall j, t, s \in S_{t} \\
I_{i t}, B_{i t} \geq 0 & \forall i, t \\
Z_{j k s} \geq 0 & \forall j, k, t, s \in S_{t} \\
Y_{j s}=\bar{Y}_{j s} & \forall j, s \in Q_{1} \cup \ldots \cup Q_{p-1} \\
Y_{j s} \in\{0,1\} & \forall j, s \in Q_{p} \\
Y_{j s} \in[0,1] & \forall j, s \in Q \backslash\left(Q_{1} \cup \ldots \cup Q_{p}\right)
\end{array}
$$

After solving all the $P$ iterations, if all the $p$ subproblems are feasible, then $\left(\bar{X}_{j s}, \bar{I}_{i t}, \bar{B}_{i t}, \bar{Y}_{j s}, \bar{Z}_{j k s}\right)$ is the feasible solution of heuristics Relax-and-Fix (Pochet \& Wolsey, 2006). Algorithm 1 presents a general algorithm for the heuristics presented in this paper. Several studies using Relax-andFix to find a good solution in a short computational time or to find an initial solution from other heuristics to lotsizing and scheduling problems can be found in the literature. The papers by Toso et al. (2009), Ferreira et al. (2010), Seeanner \& Meyr (2013), Baldo et al. (2014) and Furtado et al. (2019) are examples of lotsizing and scheduling formulations in different industries that use different heuristic strategies Relax-and-Fix to solve the MIP model. In addition, Absi \& van den 
Heuvel (2019) analyze the complexity of Relax-and-Fix heuristics and point out that their use is effective for large-scale multi-item/multi-stage lotsizing problems with capacity constraints.

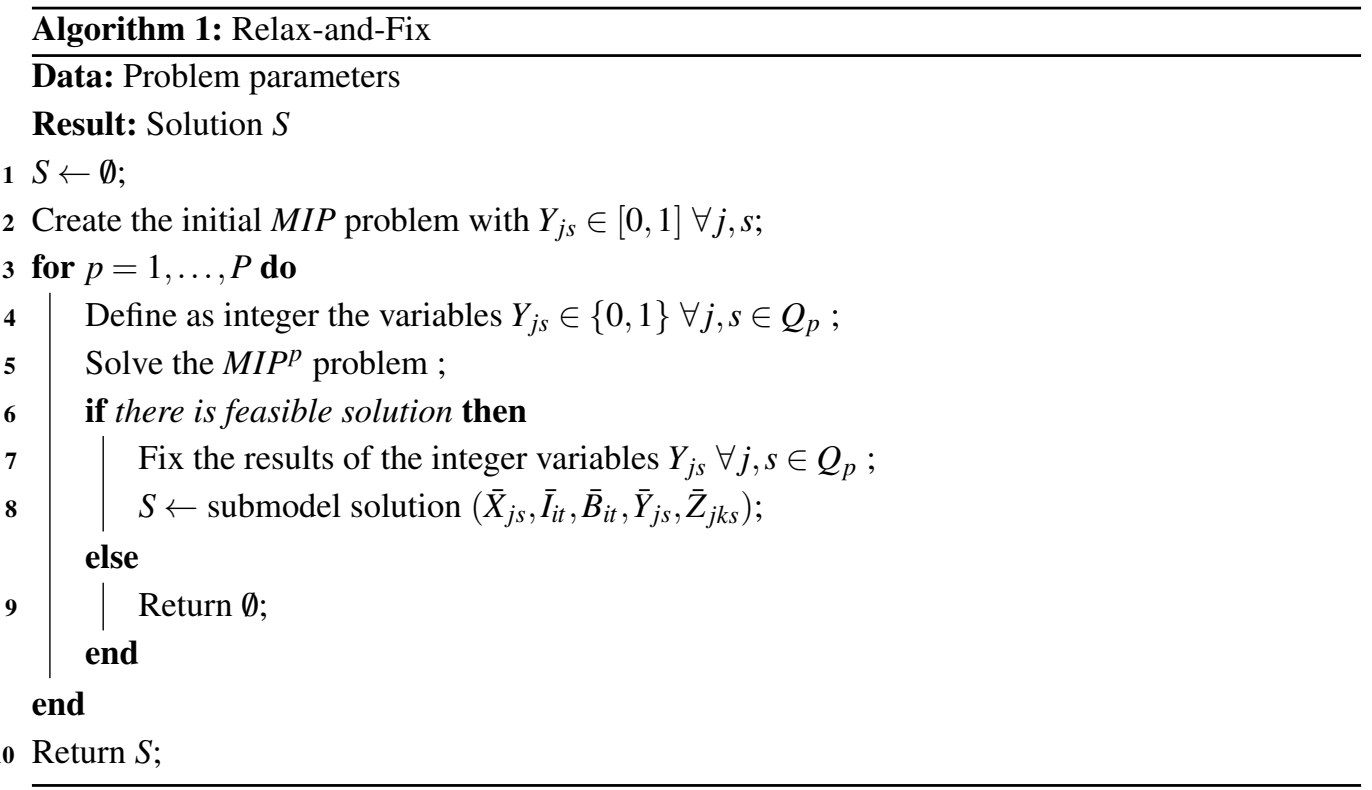

The partitioning of decision variables could vary, but the most common in the literature for the lotsizing problem is based on time periods. The lotsizing and scheduling problem with process configuration selection presented in the previous section has only the setup state variables $\left(Y_{j s}\right)$ as integers. In this case, we consider $Q_{t}=\left\{Y_{j s} \mid j \in K, s \in S_{t}\right\}$ as the set of variables of the period $t$. Besides defining how to partition the variables, the strategy for exploring the partitions can vary: from the beginning to the end of periods; from the end to the beginning of periods; and having overlapping periods with integer variables and with variables that should have their values fixed. Several strategies are explored in this paper:

Relax-and-Fix Forward: Algorithm 1 represents the heuristic. In a period-based variable partitioning, the forward strategy starts fixing the variables from the first period with the $(p=1)$ partition and ends in the last period with the partition $(p=|T|)$. That is, period-by-period, the values of the decision variables are fixed from the first period as indicated in line 3 of Algorithm 1.

Relax-and-Fix Backward: In the backward strategy, the fixing of variable values starts from the partition of the last period $p=|T|$ and ends in period $p=1$. In Algorithm 1, line 3 would be changed to "for $p=P, \ldots, 1$, step $p=p-1$ do".

Relax-and-Fix Overlapping: In this strategy, the difference is in the number of variables of the partition that have the values fixed in each iteration. The proposal is to fix values for half of the variables, for example, in iteration $p$ the second half of the variables of period $p-1$ and the first half of the sub-periods of period $p$. The second half of the variables of period $p$ remains integer and free to be optimized again together with the next period. This strategy is similar to 
Relax-and-Fix Forward, however, constraints (17) in model (12)-(19) are changed to fix values in the appropriate variables.

Relax-and-Fix Minimizes Backlogs: the strategy is similar to Forward. However, at the end of each iteration, it is checked if there is a backlog in meeting demand. If there is, the iteration is solved again with the freedom to optimize the variables of the last period previously fixed. This strategy is done until there are no more backlogs, or the variables of all periods are free for optimization (dos Santos Diz et al., 2019). In Algorithm 1, after line 5, the following loop is inserted:

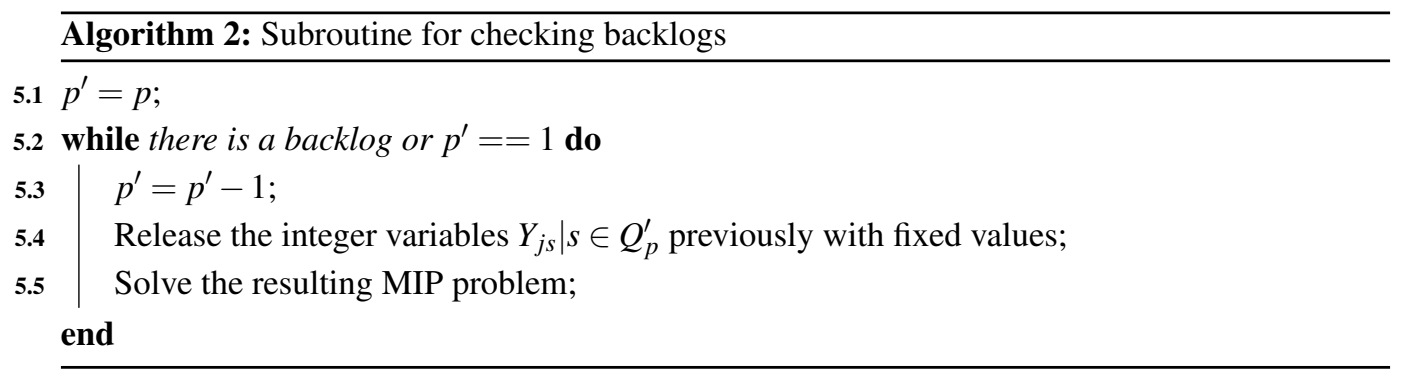

In this paper, these four strategies of Relax-and-Fix heuristics and other applications in combination with improvement heuristics are investigated and compared with each other, as described in Table 3 in the section on computational experiments.

\subsubsection{Fix-and-Optimize}

Fix-and-Optimize is an improvement heuristic, that is, it performs improvement movements in a previously given solution. The procedure consists of using the MIP model by fixing the values of the decision variables and releasing a variable partition to be optimized along with all the continuous variables. The integer variables of the model are partitioned into $P$ sets, where $Q_{p}$ is the set of variables of partition $p$, where $p=1,2, \ldots, P$. In any iteration of the method, the integer variables are fixed to the best incumbent solution $\left(\bar{Y}_{j s}\right)$. Except for iteration $p$, the variables of the set $Q_{p}$ are not fixed but are defined as integers and the following model is solved. Algorithm 3 describes the step-by-step of heuristics.

$$
\left(M I P^{p}\right) \quad \text { Minimize } \sum_{i \in N} \sum_{t \in T}\left(h_{i} I_{i t}+b_{i} B_{i t}\right)+\sum_{j, k \in K} \sum_{s \in S} c_{j k} Z_{j k s}
$$




\section{Subject to}

$$
\begin{array}{lr}
(2)-(8) & \\
X_{j s} \geq 0 & \forall j, t, s \in S_{t} \\
I_{i t}, B_{i t} \geq 0 & \forall i, t \\
Z_{j k s} \geq 0 & \forall j, k, t, s \in S_{t} \\
Y_{j s}=\bar{Y}_{j s} & \forall j, s \in Q \backslash Q_{p} \\
Y_{j s} \in\{0,1\} & \forall j, s \in Q_{p}
\end{array}
$$

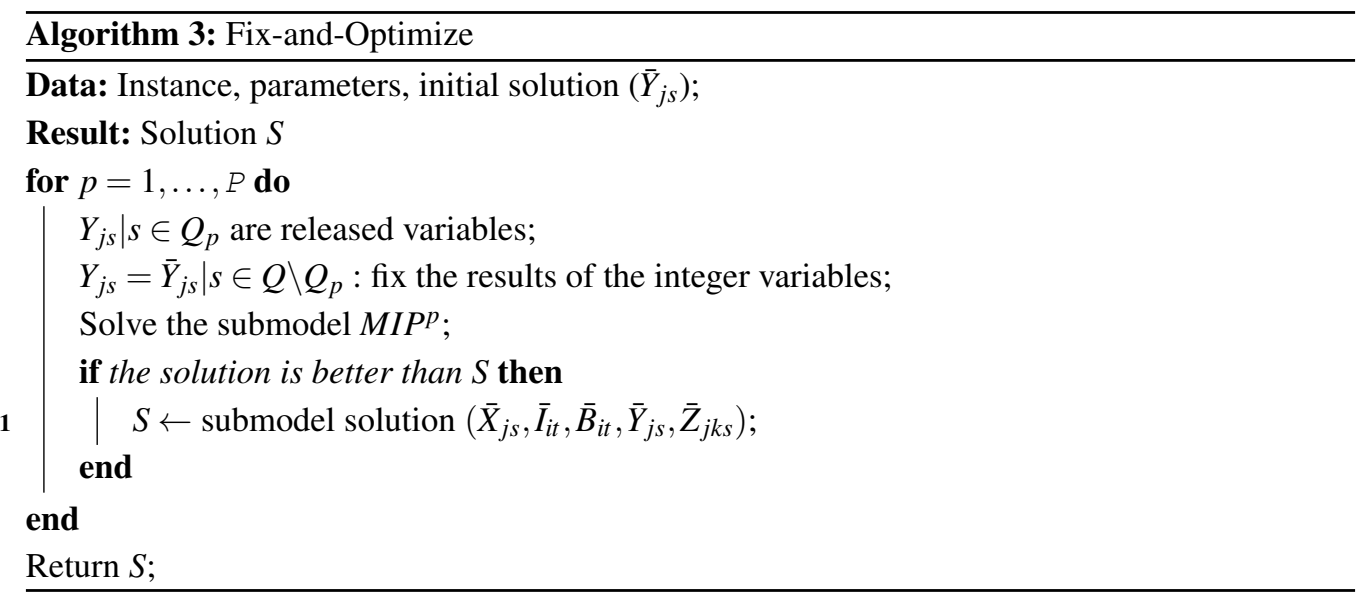

Fix-and-Optimize is well used in lotsizing and scheduling problem, mainly in combination with other constructive heuristics, such as Relax-and-Fix which provides an initial solution. The papers by Sahling et al. (2009), Helber \& Sahling (2010), Baldo et al. (2014), Toledo et al. (2015), Tempelmeier \& Copil (2016) and Soler et al. (2019) are examples of the combined application of Relax-and-Fix and Fix-and-Optimize. The partitioning of decision variables can vary, but the most common in the literature for the lotsizing problem is based on time periods. The lotsizing and scheduling problem with process configuration selection, presented in the previous section, has only the setup state variables $\left(Y_{j s}\right)$ defined as integers. In this case, the partitioning can be based on configurations ( $|K|$ partitions) or, in a classic way, based on periods ( $|T|$ partitions).

In this paper, Fix-and-Optimize is experimented with the two options of variable partitioning, by configurations and by periods. As an initial solution is required, Fix-and-Optimize is tested and compared in combination with Relax-and-Fix heuristics in several combinations, as described in Table 3 in the next section.

\section{COMPUTATIONAL EXPERIMENTS}

The computational experiments performed with the model and heuristics aim to produce results to compare the quality of the solutions obtained and the computational time to find them. 
Next, tests for the resolution of the MIP model and various combinations of MIP-heuristics are reported. The Relax-and-Fix heuristics and their combinations with the Fix-and-Optimize heuristics with partitions of the configurations and periods are tested. The experiments of five combinations of Relax-and-Fix and Fix-and-Optimize heuristics are reported. According to preliminary tests, in which 8 combinations were tested, the combinations presented below seemed more promising and only they were investigated in the study.

The instances used in computational tests represent three types of process industries and are divided into three groups each. The instances of the molded pulp packaging company were based on the real data presented in Martínez et al. (2019). The G1 and G2 groups are data cutouts, while in G3 group the data are randomly generated based on practice. The instances of the furniture company are cutouts of the instances presented in Alem et al. (2010).

The instances of the electro-fused grain company are cutouts of the instances presented in Luche et al. (2009). The cutout aims to consider a single process with a single machine.

Table 2 shows the number of variables and parameters present in the instances of each group, where $|T|$ is the number of periods, $|S|$ is the number of sub-periods, "Continuous" is the number of continuous variables and "Binary" is the number of binary variables.

Table 2 - Parameters of the instances used in the computational tests.

\begin{tabular}{|c|c|c|c|c|c|c|c|}
\hline & & Products & Configurations & $\mid \overline{|T|}$ & $|S|$ & Continuous & Binary \\
\hline \multirow{3}{*}{ Molded Pulp } & G1 & 14 & 19 & \multirow{3}{*}{4} & \multirow{3}{*}{40} & 872 & 15.200 \\
\hline & G2 & 8 & 70 & & & 2.864 & 198.800 \\
\hline & G3 & 20 & 40 & & & 1.760 & 65.600 \\
\hline \multirow{3}{*}{ Furniture } & G1 & 6 & 40 & \multirow{3}{*}{8} & \multirow{3}{*}{32} & 1.328 & 52.480 \\
\hline & G2 & 6 & 60 & & & 1.968 & 117.120 \\
\hline & G3 & 6 & 80 & & & 2.608 & 207.360 \\
\hline \multirow{3}{*}{$\begin{array}{l}\text { Electrofused } \\
\text { Grains }\end{array}$} & G1 & 5 & 50 & \multirow{3}{*}{19} & \multirow{3}{*}{57} & 2.945 & 145.350 \\
\hline & G2 & 10 & 50 & & & 3.040 & 145.350 \\
\hline & G3 & 5 & 149 & & & 8.588 & 1.273 .950 \\
\hline
\end{tabular}

\subsection{Computational results}

The computational tests were performed on a machine with an Intel i7 processor containing 16 GB of RAM. The execution time limit of CPLEX v.12.5 for each method and for each of the instances was 3,600 seconds. For heuristics, the total time was divided equally into the total number of iterations (partitions) required by the method. Thus, instances that contain more partitions provide less time per iteration, since the number of iterations is related to the number of partitions. With less time available for one iteration, the solver may not find the optimal solution for that partition. This may imply worse quality solutions at the end of the iterations when compared to other solutions that had longer solution time available. Similarly, when we compare the use of one method with $\mathrm{P}$ partitions with another method that additionally uses $\mathrm{P}$ partitions in an 
improvement procedure, there is no guarantee that the method with the improvement procedure has better solutions. This is because we cannot guarantee that each iteration finds the optimal solution.

To better understand the results, the instances were separated by industry and the objective function values, Gap and execution time are reported in Tables 4, 5 and 6. These indicators are provided for each of the MIP-heuristics tested and listed in Table 3.

Table 3 - List of the solution methods computationally tested.

\begin{tabular}{l|c}
\hline Method & Subtitles \\
\hline MIP & A \\
\hline Relax-and-Fix Backward & B \\
\hline Relax-and-Fix Forward & C \\
\hline Relax-and-Fix Overlapping & D \\
\hline Relax-and-Fix Minimizes Backlogs & E \\
\hline $\begin{array}{l}\text { Fix-and-Optimize with configuration partitions } \\
\text { and Relax-and-Fix Forward }\end{array}$ & $\mathrm{F}$ \\
\hline $\begin{array}{l}\text { Fix-and-Optimize with configuration partitions } \\
\text { and Relax-and-Fix Overlapping }\end{array}$ & $\mathrm{G}$ \\
\hline $\begin{array}{l}\text { Fix-and-Optimize with configuration partitions } \\
\text { and Relax-and-Fix Minimizes Backlogs }\end{array}$ & $\mathrm{H}$ \\
\hline $\begin{array}{l}\text { Fix-and-Optimize with period partitions } \\
\text { and Relax-and-Fix Forward }\end{array}$ & $\mathrm{I}$ \\
\hline $\begin{array}{l}\text { Fix-and-Optimize with period partitions } \\
\text { and Relax-and-Fix Overlapping }\end{array}$ & $\mathrm{J}$ \\
\hline
\end{tabular}

Besides the results for each one of the instances, Table 7 presents a general comparison considering the averages of all the instances for each indicator. In addition, the averages of the instances by industry are also reported.

\section{Molded pulp packaging industry}

In Table 4, for each of the methods, the following is presented: "OF" indicating the value found for the objective function; "Dsv" indicating the relative difference of the value of the objective function of the method from the MIP (Dsv $=100 *\left(O F^{\mathrm{Heu}} / O F^{M I P}\right)-100$, where $O F^{\mathrm{Heu}}$ represents the value of the objective function of the method and $O F^{M I P}$ represents the value of the objective function of the MIP); and "Tm" which indicates the computational time, in seconds, to reach the indicated solution using the complete strategy. It is important to note that if Dsv $<0$, the method finds a better quality solution than the MIP. In the MIP results, the "Gap" column indicates the relative difference between the lower bound $(L B)$ and upper bound $(O F)$ found by CPLEX. That is, Gap $=(O F / L B)-1$. 
Table 4 - Computational results for the molded pulp industry instances.

\begin{tabular}{|c|c|c|c|c|c|c|c|c|c|c|c|c|c|c|c|c|c|c|c|c|c|}
\hline \multirow[b]{2}{*}{ nstance } & \multicolumn{3}{|c|}{ MIP } & \multicolumn{2}{|c|}{$\begin{array}{l}\text { (B) R\&F } \\
\text { Backward }\end{array}$} & \multicolumn{2}{|c|}{$\begin{array}{l}\text { (C) } R \& F \\
\text { Forward }\end{array}$} & \multicolumn{2}{|c|}{\begin{tabular}{|c|} 
(D) R\&F \\
Overlapping
\end{tabular}} & \multicolumn{2}{|c|}{$\begin{array}{c}\text { (E) R\&F } \\
\text { Min Backlog }\end{array}$} & \multicolumn{2}{|c|}{$\begin{array}{l}\text { (F) F\&O/C + } \\
\text { R\&F Forward }\end{array}$} & \multicolumn{2}{|c|}{$\begin{array}{c}(\mathrm{G}) \mathrm{F} \& \mathrm{O} / \mathrm{C}+ \\
\mathrm{R} \& \mathrm{~F} \text { Overlapping }\end{array}$} & \multicolumn{2}{|c|}{$\begin{array}{c}\text { (H) F\&O/C + } \\
\text { R\&F Min Backlog }\end{array}$} & \multicolumn{2}{|c|}{\begin{tabular}{|c|} 
(I) $\mathrm{F} \& \mathrm{O} / \mathrm{P}+$ \\
$\mathrm{R} \& \mathrm{~F}$ Forward \\
\end{tabular}} & \multicolumn{2}{|c|}{$\begin{array}{c}\text { (J) } \mathrm{F} \& \mathrm{O} / \mathrm{P}+ \\
\mathrm{R} \& \mathrm{~F} \text { Overlapping }\end{array}$} \\
\hline & OF & Gap & $\mathrm{Tm}$ & Dsv & $\mathrm{Tm}$ & Dsv & Tm & Dsv & $\mathrm{Tm}$ & Dsv & $\mathrm{Tm}$ & Dsv & $\mathrm{Tm}$ & Dsv & $\mathrm{Tm}$ & Dsv & $\mathrm{Tm}$ & Dsv & $\mathrm{Tm}$ & Dsv & $\mathrm{Tm}$ \\
\hline G1_Ex1 & 81457 & $24.0 \%$ & 3600 & $3.2 \%$ & 86 & $0.0 \%$ & 42 & $0.0 \%$ & 138 & $0.0 \%$ & 82 & $0.0 \%$ & 54 & $0.9 \%$ & 151 & $0.0 \%$ & 85 & $0.0 \%$ & \begin{tabular}{l|l|}
49 \\
\end{tabular} & $0.0 \%$ & 146 \\
\hline G1_Ex2 & 41427 & $0.0 \%$ & 110 & $6.0 \%$ & 14 & $8.8 \%$ & 12 & $0.6 \%$ & 35 & $6.1 \%$ & 12 & $0.3 \%$ & 21 & $0.0 \%$ & 42 & $0.3 \%$ & 14 & $8.8 \%$ & 17 & $0.0 \%$ & 39 \\
\hline 1 1_Ex3 & 38680 & $0.0 \%$ & 255 & $4.7 \%$ & 40 & $20.8 \%$ & 25 & $1.3 \%$ & 58 & $7.4 \%$ & 59 & $0.7 \%$ & 32 & $0.6 \%$ & 66 & $0.7 \%$ & 61 & $20.2 \%$ & 30 & $0.7 \%$ & 64 \\
\hline 1_Ex4 & 50089 & $0.0 \%$ & 139 & $.9 \%$ & 23 & $.0 \%$ & 9 & $0.0 \%$ & 31 & $3.0 \%$ & 24 & $0.0 \%$ & 15 & $0.0 \%$ & 32 & $0.0 \%$ & 28 & $16.0 \%$ & 12 & $0.0 \%$ & 35 \\
\hline Ex5 & 41507 & $0.0 \%$ & 351 & $6 \%$ & 37 & $.9 \%$ & 43 & $0.6 \%$ & 57 & $8.4 \%$ & 62 & $0.5 \%$ & 58 & $0.0 \%$ & 68 & $0.5 \%$ & 69 & $17.2 \%$ & 54 & $0.0 \%$ & 62 \\
\hline 1_Ex6 & 120020 & $8.0 \%$ & 3600 & $1 \%$ & 57 & $6.1 \%$ & 15 & $0.4 \%$ & 58 & $-2.3 \%$ & 109 & $0.7 \%$ & 27 & $0.5 \%$ & 65 & $0.7 \%$ & 20 & $5.1 \%$ & 21 & $0.1 \%$ & 61 \\
\hline 1_Ex7 & 101273 & $0.0 \%$ & 254 & $8 \%$ & 24 & $3.9 \%$ & 7 & $1.0 \%$ & 33 & $0.0 \%$ & 14 & $0.9 \%$ & 34 & $0.9 \%$ & 39 & $.9 \%$ & 23 & $3.9 \%$ & 32 & $1.0 \%$ & 36 \\
\hline 1_Ex8 & 129908 & $10.0 \%$ & 3600 & $.0 \%$ & 74 & $1.1 \%$ & 26 & $0.0 \%$ & 167 & $-1.6 \%$ & 175 & $0.7 \%$ & 46 & $0.0 \%$ & 276 & $0.7 \%$ & 180 & $1.1 \%$ & 45 & $0.0 \%$ & 176 \\
\hline $\mathrm{Ex} 9$ & 74892 & $3.0 \%$ & 3600 & $48.8 \%$ & 61 & $4.7 \%$ & 30 & $1.2 \%$ & 74 & $4.2 \%$ & 66 & $0.9 \%$ & 50 & $0.5 \%$ & 88 & $0.9 \%$ & 77 & $1.1 \%$ & 48 & $1.2 \%$ & 85 \\
\hline$x 10$ & 37060 & $0.0 \%$ & 288 & $5.4 \%$ & 60 & $0.5 \%$ & 50 & $0.0 \%$ & 94 & $0.3 \%$ & 54 & $0.3 \%$ & 96 & $0.0 \%$ & 109 & $0.3 \%$ & 71 & $0.5 \%$ & 91 & $0.0 \%$ & 105 \\
\hline 1_Ex11 & 40206 & $0.0 \%$ & 178 & $4.2 \%$ & 43 & $.6 \%$ & 29 & $8.4 \%$ & 39 & $20.3 \%$ & 30 & $0.0 \%$ & 37 & $0.4 \%$ & 50 & $0.0 \%$ & 48 & $23.9 \%$ & 34 & $7.1 \%$ & 44 \\
\hline 2_Ex1 & 304224 & $37.0 \%$ & 3600 & $23.4 \%$ & 162 & $5.4 \%$ & 944 & $5.4 \%$ & 1051 & $5.4 \%$ & 1080 & $0.8 \%$ & 2132 & $0.1 \%$ & 2532 & $0.1 \%$ & 2538 & $3.5 \%$ & 2121 & $3.5 \%$ & 2521 \\
\hline 2_Ex2 & 194559 & $0.0 \%$ & 164 & $.6 \%$ & 55 & $.8 \%$ & 184 & $8 \%$ & 189 & $5.8 \%$ & 242 & $0.0 \%$ & 384 & $0.0 \%$ & 291 & $0.0 \%$ & 355 & $0.0 \%$ & 377 & $0.0 \%$ & 276 \\
\hline G2_Ex3 & 213477 & $0.0 \%$ & 2007 & $3 \%$ & 523 & $.9 \%$ & 265 & $1.0 \%$ & 734 & $25.8 \%$ & 600 & $22.4 \%$ & 351 & $17.2 \%$ & 852 & $14.8 \%$ & 729 & $30.9 \%$ & 345 & $21.0 \%$ & 850 \\
\hline G2_Ex4 & 183707 & $0.0 \%$ & 2066 & $447.7 \%$ & 143 & $0.0 \%$ & 126 & $0.0 \%$ & 502 & $0.0 \%$ & 572 & $0.0 \%$ & 212 & $0.0 \%$ & 1259 & $0.0 \%$ & 794 & $0.0 \%$ & 207 & $0.0 \%$ & 1257 \\
\hline G2_Ex5 & 208644 & $0.0 \%$ & 1248 & $55.8 \%$ & 1164 & $46.0 \%$ & 669 & $4.5 \%$ & 823 & $38.7 \%$ & 676 & $5.5 \%$ & 756 & $1.7 \%$ & 888 & $1.7 \%$ & 743 & $46.0 \%$ & 748 & $4.5 \%$ & 885 \\
\hline G2_Ex6 & 237976 & $14.0 \%$ & 3600 & $29.0 \%$ & 1961 & $3.1 \%$ & 108 & $5.8 \%$ & 653 & $9.1 \%$ & 827 & $1.9 \%$ & 565 & $0.3 \%$ & 790 & $0.3 \%$ & 1306 & $10.1 \%$ & 555 & $2.4 \%$ & 789 \\
\hline G2_Ex7 & 232570 & $33.0 \%$ & 3600 & $64.7 \%$ & 862 & $4.9 \%$ & 212 & $1.8 \%$ & 803 & $-0.9 \%$ & 828 & $2.9 \%$ & 312 & $0.2 \%$ & 873 & $0.2 \%$ & 913 & $4.9 \%$ & 305 & $1.8 \%$ & 871 \\
\hline G2_Ex8 & 196859 & $0.0 \%$ & 2268 & $17.1 \%$ & 140 & $4.7 \%$ & 109 & $9.8 \%$ & 318 & $10.4 \%$ & 193 & $8.5 \%$ & 226 & $0.0 \%$ & 2809 & $0.0 \%$ & 2105 & $24.7 \%$ & 220 & $0.0 \%$ & 2801 \\
\hline G2_Ex9 & 189025 & $0.0 \%$ & 3542 & $61.7 \%$ & 723 & $5.0 \%$ & 998 & $9.3 \%$ & 1015 & $20.5 \%$ & 1311 & $13.6 \%$ & 1424 & $1.6 \%$ & 2579 & $1.6 \%$ & 2589 & $17.0 \%$ & 1421 & $2.2 \%$ & 2575 \\
\hline G2_Ex10 & 179625 & $0.0 \%$ & 1998 & $94.2 \%$ & 114 & $2.0 \%$ & 55 & $2.6 \%$ & 67 & $0.8 \%$ & 77 & $2.6 \%$ & 347 & $2.4 \%$ & 134 & $2.4 \%$ & 218 & $2.6 \%$ & 335 & $2.6 \%$ & 127 \\
\hline G3_Ex1 & 59402 & $42.0 \%$ & 3600 & $.5 \%$ & 214 & $.0 \%$ & 294 & $4.0 \%$ & 1398 & $12.3 \%$ & 614 & $3.4 \%$ & 35 & $2.1 \%$ & 1430 & $2.1 \%$ & 651 & $10.6 \%$ & 339 & $12.6 \%$ & 1424 \\
\hline$x 2$ & 63663 & $27.0 \%$ & 3600 & $.2 \%$ & 357 & $6.7 \%$ & 1279 & $6.7 \%$ & 1140 & $2.7 \%$ & 1478 & $2.2 \%$ & 1352 & $1.6 \%$ & 1160 & $2.2 \%$ & 1534 & $6.7 \%$ & 1338 & $4.3 \%$ & 1157 \\
\hline$x 3$ & 58104 & $0.0 \%$ & 3386 & $51.9 \%$ & 179 & $.9 \%$ & 175 & $1.1 \%$ & 1186 & $23.6 \%$ & 965 & $12.9 \%$ & 218 & $0.5 \%$ & 1209 & $0.5 \%$ & 1000 & $22.7 \%$ & 211 & $1.1 \%$ & 1200 \\
\hline G3_Ex4 & 80886 & $48.0 \%$ & 3600 & $53.7 \%$ & 479 & $-0.5 \%$ & 811 & $-4.0 \%$ & 1704 & $-3.6 \%$ & 1453 & $-3.1 \%$ & 849 & $-4.2 \%$ & 1743 & $-3.1 \%$ & 1495 & $-0.5 \%$ & 841 & $-4.0 \%$ & 1735 \\
\hline G3_Ex5 & 66135 & $36.0 \%$ & 3600 & $5.6 \%$ & 545 & $2.6 \%$ & 275 & $1.4 \%$ & 1282 & $-2.1 \%$ & 943 & $-0.7 \%$ & 325 & $-1.6 \%$ & 1309 & $-0.7 \%$ & 983 & $2.6 \%$ & 316 & $1.4 \%$ & 1306 \\
\hline G3_Ex6 & 89378 & $.0 \%$ & 3600 & $6.5 \%$ & 1430 & $8.3 \%$ & 2992 & $-1.2 \%$ & 3522 & $2.8 \%$ & 3343 & $0.2 \%$ & 3056 & $-3.9 \%$ & 3570 & $0.2 \%$ & 3396 & $8.3 \%$ & 3040 & $-1.2 \%$ & 3564 \\
\hline G3_Ex7 & 87112 & $5.0 \%$ & 3600 & $5.6 \%$ & 1125 & $6.1 \%$ & 1765 & $-3.4 \%$ & 2930 & $8.4 \%$ & 2755 & $1.6 \%$ & 1988 & $-10.3 \%$ & 2853 & $-0.5 \%$ & 2806 & $34.5 \%$ & 1896 & $-10.4 \%$ & 2948 \\
\hline G3_Ex8 & 66775 & $1.0 \%$ & 3600 & $34.2 \%$ & 341 & $21.8 \%$ & 175 & $7.9 \%$ & 1184 & $19.9 \%$ & 1186 & $0.4 \%$ & 210 & $0.0 \%$ & 1229 & $0.4 \%$ & 1219 & $20.6 \%$ & 197 & $7.9 \%$ & 1214 \\
\hline G3_Ex9 & 56762 & $1.0 \%$ & 3600 & $3.4 \%$ & 56 & $12.7 \%$ & 190 & $-0.9 \%$ & 496 & $0.5 \%$ & 523 & $9.6 \%$ & 240 & $-1.4 \%$ & 870 & $-1.4 \%$ & 828 & $12.7 \%$ & 239 & $-0.9 \%$ & 858 \\
\hline G3_Ex10 & 59418 & $16.0 \%$ & 3600 & $158.6 \%$ & 273 & $8.6 \%$ & 143 & $8.1 \%$ & 550 & $5.0 \%$ & 217 & $2.2 \%$ & 202 & $0.0 \%$ & 590 & $0.0 \%$ & 273 & $8.0 \%$ & 199 & $8.1 \%$ & 587 \\
\hline G3_Ex11 & 55275 & $27.0 \%$ & 3600 & $78.9 \%$ & 340 & $25.8 \%$ & 1070 & $10.9 \%$ & 1504 & $13.2 \%$ & 1461 & $12.1 \%$ & 1103 & $4.8 \%$ & 1541 & $2.6 \%$ & 1500 & $25.8 \%$ & 1094 & $10.9 \%$ & 1536 \\
\hline G3_Ex12 & 78080 & $56.0 \%$ & 3600 & $103.8 \%$ & 1891 & $17.9 \%$ & 1438 & $6.7 \%$ & 1548 & $13.6 \%$ & 1452 & $10.6 \%$ & 1471 & $4.3 \%$ & 2093 & $4.3 \%$ & 1971 & $17.9 \%$ & 1465 & $5.1 \%$ & 2091 \\
\hline
\end{tabular}


Table 4 shows that CPLEX finds the optimal solution of the MIP solely for several instances of group G1 - with a small number of periods and configurations. On the other hand, the solver stopped due to the time limit for most of the instances of the G3 group, presented high optimality gaps. Among the MIP-heuristics, the (B) Relax-and-Fix Backward is the method that presented the worst performance. The Fix-and-Optimize methods with configuration partitions using Relax-and-Fix Overlapping heuristics (G) or Relax-and-Fix that minimizes backlogs (H) presented the best performances for the groups of instances of the molded pulp packaging industry.

Regarding the computational time, the (B) Relax-and-Fix Backward method consumes, in general, the shortest time - on average 407 seconds. On the other hand, the (G) Fix-and-Optimize with configuration partitions combined with Relax-and-Fix Overlapping has the highest average consumption, with 977 seconds.

\section{Furniture Industry}

Similarly to the previous table, the results shown in Table 5 present the same indicators used for comparing solution methods for the furniture industry.

Table 5 shows that CPLEX stops by time limit for all instances solved by MIP solely. The G1 group solutions have a $8 \%$ gap of the optimal solution, the G2 group has more than $13 \%$ and the G3 results have more than $47 \%$. Once more, the (B) Relax-and-Fix Backward is the method that presented the worst performance. The Fix-and-Optimize methods with configuration partitions using Relax-and-Fix that minimize backlogs $(\mathrm{H})$ or Relax-and-Fix Overlapping $(\mathrm{G})$ presented the best performances for the groups of instances of the furniture industry.

Regarding the computational time, the (B) Relax-and-Fix Backward method consumes, on average, a shorter time - 139 seconds. On the other hand, the $(\mathrm{H})$ Fix-and-Optimize with configuration partitions using Relax-and-Fix that minimizes backlogs has the highest average runtime consumption, with 1793 seconds. 
Table 5 - Computational results for the furniture industry instances.

\begin{tabular}{|c|c|c|c|c|c|c|c|c|c|c|c|c|c|c|c|c|c|c|c|c|c|}
\hline & \multicolumn{3}{|c|}{ MIP } & \multicolumn{2}{|c|}{$\begin{array}{l}\text { (B) R\&F } \\
\text { Backward }\end{array}$} & \multicolumn{2}{|c|}{$\begin{array}{l}\text { (C) } \mathrm{R} \& \mathrm{~F} \\
\text { Forward }\end{array}$} & \multicolumn{2}{|c|}{$\begin{array}{c}\text { (D) } \mathrm{R} \& \mathrm{~F} \\
\text { Overlapping }\end{array}$} & \multicolumn{2}{|c|}{$\begin{array}{c}\text { (E) R\&F } \\
\text { Min Backlog }\end{array}$} & \multicolumn{2}{|c|}{$\begin{array}{l}\text { (F) F\&O/C + } \\
\text { R\&F Forward }\end{array}$} & \multicolumn{2}{|c|}{$\begin{array}{c}\text { (G) } \mathrm{F} \& \mathrm{O} / \mathrm{C}+ \\
\mathrm{R} \& \mathrm{~F} \text { Overlapping }\end{array}$} & \multicolumn{2}{|c|}{$\begin{array}{c}\text { (H) F\&O/C + } \\
\text { R\&F Min Backlog }\end{array}$} & \multicolumn{2}{|c|}{$\begin{array}{l}\text { (I) } \mathrm{F} \& \mathrm{O} / \mathrm{P}+ \\
\mathrm{R} \& \mathrm{~F} \text { Forward }\end{array}$} & \multicolumn{2}{|c|}{$\begin{array}{c}\text { (J) } \mathrm{F} \& \mathrm{O} / \mathrm{P}+ \\
\mathrm{R} \& \mathrm{~F} \text { Overlapping }\end{array}$} \\
\hline Instância & OF & Gap & $\mathrm{Tm}$ & Dsv & $\mathrm{Tm}$ & Dsv & $\mathrm{Tm}$ & Dsv & $\mathrm{Tm}$ & Dsv & $\mathrm{Tm}$ & Dsv & $\mathrm{Tm}$ & Dsv & $\mathrm{Tm}$ & Dsv & $\mathrm{Tm}$ & Dsv & $\mathrm{Tm}$ & Dsv & $\mathrm{Tm}$ \\
\hline G1_Ex1 & 510 & $9.0 \%$ & 3600 & $86.0 \%$ & 106 & $1.0 \%$ & 164 & $1.0 \%$ & 220 & $-1.9 \%$ & 364 & $1.0 \%$ & 484 & $1.0 \%$ & 459 & $-3.7 \%$ & 548 & $1.1 \%$ & 478 & $1.1 \%$ & 442 \\
\hline G1_Ex2 & 542 & $8.0 \%$ & 3600 & $53.0 \%$ & 124 & $4.0 \%$ & 146 & $3.0 \%$ & 267 & $3.8 \%$ & 223 & $2.9 \%$ & 307 & $1.9 \%$ & 572 & $1.9 \%$ & 898 & $3.1 \%$ & 298 & $1.1 \%$ & 551 \\
\hline G1_Ex3 & 594 & $8.0 \%$ & 3600 & $111.0 \%$ & 188 & $6.0 \%$ & 96 & $0.0 \%$ & 211 & $0.0 \%$ & 343 & $1.7 \%$ & 240 & $-0.3 \%$ & 328 & $-3.3 \%$ & 550 & $4.0 \%$ & 232 & $0.0 \%$ & 324 \\
\hline G1_Ex4 & 569 & $8.0 \%$ & 3600 & $36.0 \%$ & 177 & $5.0 \%$ & 174 & $1.0 \%$ & 278 & $4.8 \%$ & 354 & $3.6 \%$ & 316 & $2.6 \%$ & 601 & $2.6 \%$ & 823 & $4.9 \%$ & 315 & $0.9 \%$ & 595 \\
\hline G1_Ex5 & 562 & $11.0 \%$ & 3600 & $63.0 \%$ & 174 & $6.0 \%$ & 167 & $2.0 \%$ & 337 & $-1.8 \%$ & 311 & $0.9 \%$ & 531 & $0.5 \%$ & 655 & $-1.8 \%$ & 942 & $1.0 \%$ & 517 & $1.0 \%$ & 628 \\
\hline G2_Ex1 & 442 & $13.0 \%$ & 3600 & $55.0 \%$ & 153 & $21.0 \%$ & 99 & $5.0 \%$ & 349 & $3.8 \%$ & 749 & $5.6 \%$ & 735 & $3.6 \%$ & 805 & $3.6 \%$ & 1110 & $7.0 \%$ & 687 & $3.8 \%$ & 772 \\
\hline G2_Ex2 & 579 & $16.0 \%$ & 3600 & $103.0 \%$ & 108 & $1.0 \%$ & 265 & $1.0 \%$ & 867 & $-5.2 \%$ & 906 & $-1.7 \%$ & 840 & $-2.0 \%$ & 1358 & $-6.2 \%$ & 1728 & $1.0 \%$ & 804 & $1.1 \%$ & 1324 \\
\hline G2_Ex3 & 475 & $25.0 \%$ & 3600 & $62.0 \%$ & 117 & $10.0 \%$ & 185 & $5.0 \%$ & 772 & $-0.4 \%$ & 603 & $2.5 \%$ & 518 & $-0.1 \%$ & 1143 & $-1.3 \%$ & 1707 & $3.1 \%$ & 498 & $3.9 \%$ & 1118 \\
\hline G2_Ex4 & 486 & $25.0 \%$ & 3600 & $49.0 \%$ & 174 & $10.0 \%$ & 153 & $1.0 \%$ & 896 & $1.7 \%$ & 713 & $5.8 \%$ & 743 & $3.4 \%$ & 1159 & $-0.2 \%$ & 1678 & $7.0 \%$ & 690 & $0.1 \%$ & 1155 \\
\hline G2_Ex5 & 495 & $24.0 \%$ & 3600 & $89.0 \%$ & 148 & $0.0 \%$ & 104 & $0.0 \%$ & 552 & $-0.8 \%$ & 866 & $-0.1 \%$ & 381 & $-1.1 \%$ & 820 & $-2.1 \%$ & 1169 & $-0.1 \%$ & 367 & $-0.2 \%$ & 809 \\
\hline G3_Ex1 & 267 & $50.0 \%$ & 3600 & $75.0 \%$ & 147 & $-4.0 \%$ & 641 & $-4.0 \%$ & 961 & $-10.7 \%$ & 1087 & $-4.0 \%$ & 1594 & $-4.5 \%$ & 1815 & $-10.7 \%$ & 3358 & $-4.0 \%$ & 1494 & $-3.9 \%$ & 1746 \\
\hline G3_Ex2 & 235 & $47.0 \%$ & 3600 & $13.0 \%$ & 97 & $2.0 \%$ & 358 & $2.0 \%$ & 934 & $-2.7 \%$ & 1053 & $-1.5 \%$ & 1390 & $-2.4 \%$ & 1924 & $-3.7 \%$ & 3569 & $-0.7 \%$ & 1325 & $-2.1 \%$ & 1845 \\
\hline G3_Ex3 & 207 & $64.0 \%$ & 3600 & $49.0 \%$ & 109 & $4.0 \%$ & 226 & $2.0 \%$ & 814 & $0.7 \%$ & 1162 & $3.2 \%$ & 867 & $1.2 \%$ & 2012 & $-1.6 \%$ & 2891 & $3.2 \%$ & 855 & $2.2 \%$ & 1902 \\
\hline Ex4 & 214 & $61.0 \%$ & 3600 & $93.0 \%$ & 110 & $-1.0 \%$ & 495 & $-1.0 \%$ & 949 & $-3.2 \%$ & 1451 & $-3.5 \%$ & 1179 & $-5.4 \%$ & 1564 & $-5.4 \%$ & 2535 & $-0.9 \%$ & 1109 & $-0.8 \%$ & 1554 \\
\hline G3_Ex5 & 237 & $63.0 \%$ & 3600 & $85.0 \%$ & 158 & $-2.0 \%$ & 126 & $-2.0 \%$ & 983 & $-7.0 \%$ & 864 & $-5.3 \%$ & 1345 & $-6.3 \%$ & 2259 & $-10.4 \%$ & 3398 & $-4.1 \%$ & 1255 & $-4.0 \%$ & 2182 \\
\hline
\end{tabular}




\section{Electrofused grain industry}

Table 6 presents the results for the tests with the instances of the electrofused grain industry. The same indicators as the previous tables are used for comparison.

Table 6 shows that CPLEX stops by time limit for all instances solved by mathematical modeling (MIP). The G1 group solutions have a 10\% gap of the optimal solution, the G2 group has more than $20 \%$ and the G3 results have more than $60 \%$ of the optimality. Once more, (B) Relax-andFix Backward is the method with the worst performance. The Fix-and-Optimize methods with configuration partitions using Relax-and-Fix, which minimizes backlogs $(\mathrm{H})$ or Relax-and-Fix Overlapping $(\mathrm{G})$, presented the best performances for the groups of instances of the molded pulp packaging industry.

Regarding computational time, the (C) Relax-and-Fix Forward and (H) Fix-and-Optimize methods with configuration partitions combined with Relax-and-Fix that minimize backlogs consume, on average, less time - 549 and 553, seconds respectively. On the other hand, (G) Fixand-Optimize with configuration partitions combined with Relax-and-Fix Overlapping has the highest average computational time consumption, at 1417 seconds.

\section{Overall comparison}

By analyzing the results of the previous tables, it can be understood that the mathematical modeling resolution (MIP) using CPLEX found optimal solutions only for some small instances (considering the number of binary variables). For larger instances, the solver stops by the time limit and presents high optimality gaps. This result justifies the use of heuristic methods of resolution for this model.

Using Table 7, we can analyze the averages by groups of instances and overall average by method. To support the solution quality analysis, we use a color scale over the "Dsv" column that must be observed per group of instances. The greener the cell, the smaller the "Dsv" value. On the other hand, the redder the cell, the higher the value of "Dsv". For example, for the G1 group of instances of the molded pulp packaging industry, the highest result for "Dsv" is (B) Relax-andFix Backward method and the lowest results are methods $(F),(\mathrm{G})$ and $(\mathrm{H})$. Note that the table is divided into two parts so that the results can be visualized better.

Among the methods that most present "Dsv" values in green, and as we can see through the "Average" lines of the table, the $(\mathrm{H})$ Fix-and-Optimize method with configuration partitions that use Relax-and-Fix that minimizes backlogs is what presents the better results. The negative value indicates that the method found solutions that were, on average, $-0.7 \%$ better than the solutions reported when MIP solely was solved with CPLEX. In addition, we can note that CPLEX consumed, on average, 3217 seconds to solve the MIP and Fix-and-Optimize with configuration partitions that use Relax-and-Fix that minimizes backlogs consumed, on average, 1085 seconds to present slightly better results. 
Table 6 - Computational results for the instances of the electrofused grain industry.

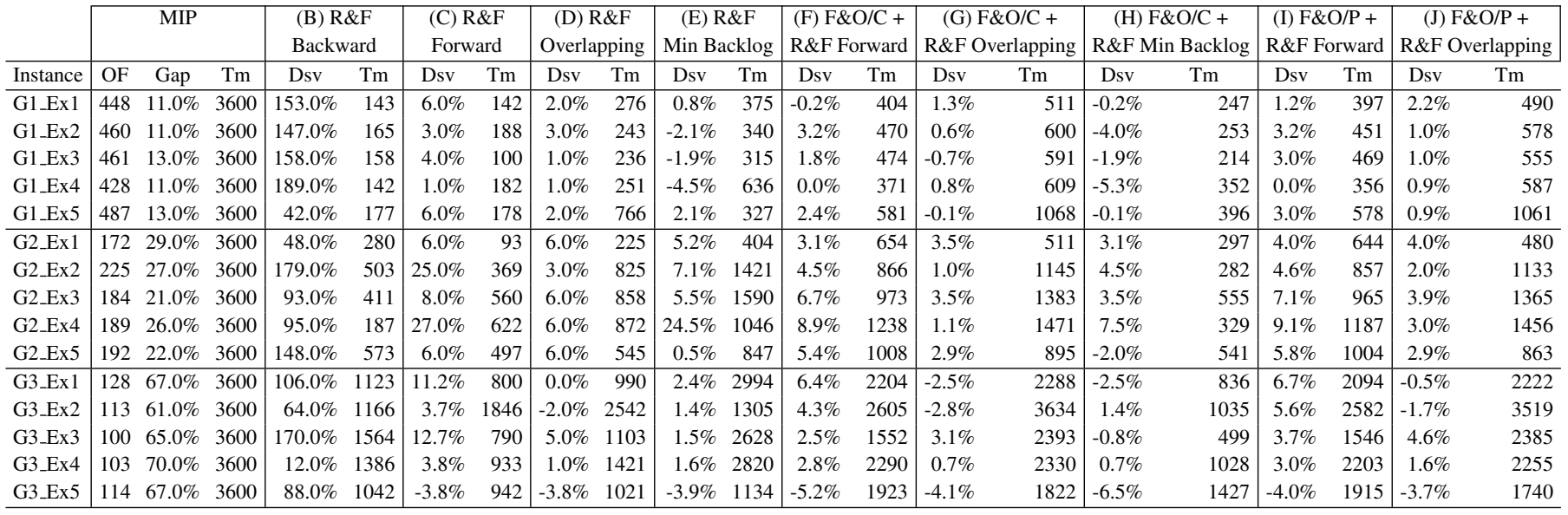


Table 7 - Average results of compilation by method and group of tested instances.

\begin{tabular}{|c|c|c|c|c|c|c|c|c|c|c|c|c|}
\hline & \multicolumn{3}{|c|}{ (A) MIP } & \multicolumn{2}{|c|}{$\begin{array}{l}\text { (B) R\&F } \\
\text { Backward }\end{array}$} & \multicolumn{2}{|c|}{$\begin{array}{l}\text { (C) } \mathrm{R} \& \mathrm{~F} \\
\text { Forward }\end{array}$} & \multicolumn{2}{|c|}{$\begin{array}{c}\text { (D) } \mathrm{R} \& \mathrm{~F} \\
\text { Overlapping }\end{array}$} & \multicolumn{2}{|c|}{$\begin{array}{c}\text { (E) R\&F } \\
\text { Min Backlog }\end{array}$} \\
\hline & & OF & Gap & $\mathrm{Tm}$ & Dsv & $\mathrm{Tm}$ & Dsv & $\mathrm{Tm}$ & Dsv & $\mathrm{Tm}$ & Dsv & $\mathrm{Tm}$ \\
\hline \multirow{3}{*}{ Molded Pulp } & G1 & 68775 & $4.1 \%$ & 1452 & $12.8 \%$ & 47 & $7.1 \%$ & 26 & $0.9 \%$ & 71 & $2.3 \%$ & 62 \\
\hline & G2 & 200858 & $8.0 \%$ & 2322 & $97.5 \%$ & 536 & $17.8 \%$ & 336 & $8.2 \%$ & 566 & $12.9 \%$ & 588 \\
\hline & G3 & 69235 & $34.1 \%$ & 3581 & $107.1 \%$ & 638 & $15.0 \%$ & 937 & $2.6 \%$ & 1550 & $8.4 \%$ & 1434 \\
\hline \multirow{3}{*}{ Furniture } & G1 & 555 & $8.8 \%$ & 3600 & $70.0 \%$ & 154 & $4.5 \%$ & 149 & 1.4 & 263 & $1.0 \%$ & 319 \\
\hline & G2 & 496 & $20.6 \%$ & 3600 & $73.2 \%$ & 140 & $7.9 \%$ & 161 & $2.3 \%$ & 687 & $-0.5 \%$ & 767 \\
\hline & G3 & 232 & $57.0 \%$ & 3600 & $63.2 \%$ & 124 & $-0.4 \%$ & 369 & $-0.8 \%$ & 928 & $-4.9 \%$ & 1123 \\
\hline \multirow{3}{*}{$\begin{array}{l}\text { Electrofused } \\
\text { Grains }\end{array}$} & G1 & 457 & $11.8 \%$ & 3600 & $135.9 \%$ & 157 & $4.1 \%$ & 158 & $1.8 \%$ & 355 & $-1.0 \%$ & 399 \\
\hline & G2 & 192 & $25.0 \%$ & 3600 & $116.5 \%$ & 391 & $14.9 \%$ & 428 & $5.3 \%$ & 665 & $8.6 \%$ & 1062 \\
\hline & G3 & 112 & $66.0 \%$ & 3600 & $87.9 \%$ & 1256 & $5.5 \%$ & 1062 & $-0.1 \%$ & 1415 & $0.6 \%$ & 2176 \\
\hline \multicolumn{2}{|l|}{ Average } & 37879 & $26.2 \%$ & 3217 & $84.9 \%$ & 383 & $8.5 \%$ & 403 & $2.4 \%$ & 722 & $3.0 \%$ & 881 \\
\hline
\end{tabular}

\begin{tabular}{|c|c|c|c|c|c|c|c|c|c|c|c|}
\hline & & \multicolumn{2}{|c|}{$\begin{array}{l}\text { (F) } \mathrm{F} \& \mathrm{O} / \mathrm{C}+ \\
\mathrm{R} \& \mathrm{~F} \text { Forward }\end{array}$} & \multicolumn{2}{|c|}{$\begin{array}{c}\text { (G) } \mathrm{F} \& \mathrm{O} / \mathrm{C}+ \\
\mathrm{R} \& \mathrm{~F} \text { Overlapping }\end{array}$} & \multicolumn{2}{|c|}{$\begin{array}{c}\text { (H) F\&O/C + } \\
\text { R\&F Min Backlog }\end{array}$} & \multicolumn{2}{|c|}{$\begin{array}{l}\text { (I) } \mathrm{F} \& \mathrm{O} / \mathrm{P}+ \\
\mathrm{R} \& \mathrm{~F} \text { Forward }\end{array}$} & \multicolumn{2}{|c|}{$\begin{array}{c}\text { (J) } \mathrm{F} \& \mathrm{O} / \mathrm{P}+ \\
\mathrm{R} \& \mathrm{~F} \text { Overlapping }\end{array}$} \\
\hline & & Dsv & $\mathrm{Tm}$ & Dsv & $\mathrm{Tm}$ & Dsv & $\mathrm{Tm}$ & Dsv & $\mathrm{Tm}$ & Dsv & $\mathrm{Tm}$ \\
\hline & G1 & $0.6 \%$ & 43 & $0.4 \%$ & 90 & $0.5 \%$ & 62 & $6.4 \%$ & 39 & $-5.4 \%$ & 78 \\
\hline \multirow[t]{3}{*}{ Molded Pulp } & G2 & $5.5 \%$ & 614 & $2.2 \%$ & 1191 & $2.0 \%$ & 1123 & $13.5 \%$ & 607 & $3.8 \%$ & 1184 \\
\hline & G3 & $3.9 \%$ & 1001 & $-1.4 \%$ & 1651 & $0.4 \%$ & 1546 & $14.5 \%$ & 985 & $1.4 \%$ & 1654 \\
\hline & G1 & $2.0 \%$ & 376 & $1.1 \%$ & 523 & $-0.8 \%$ & 752 & $2.9 \%$ & 368 & $0.8 \%$ & 508 \\
\hline \multirow{2}{*}{ Furniture } & $\mathrm{G} 2$ & $2.2 \%$ & 643 & $0.6 \%$ & 1057 & $-1.5 \%$ & 1478 & $3.4 \%$ & 609 & $1.7 \%$ & 1035 \\
\hline & G3 & $-2.4 \%$ & 1275 & $-3.6 \%$ & 1915 & $-6.6 \%$ & 3150 & $-1.5 \%$ & 1208 & $-1.9 \%$ & 1846 \\
\hline \multirow{3}{*}{$\begin{array}{l}\text { Electrofused } \\
\text { Grains }\end{array}$} & G1 & $1.5 \%$ & 460 & $0.4 \%$ & 676 & $-2.2 \%$ & 293 & $2.1 \%$ & 450 & $1.2 \%$ & 654 \\
\hline & $\mathrm{G} 2$ & $5.7 \%$ & 948 & $2.3 \%$ & 1081 & $3.4 \%$ & 401 & $6.1 \%$ & 931 & $3.1 \%$ & 1059 \\
\hline & G3 & $2.3 \%$ & 2115 & $-1.3 \%$ & 2493 & $-1.6 \%$ & 965 & $3.1 \%$ & 2068 & $-0.1 \%$ & 2424 \\
\hline Average & & $2.4 \%$ & 831 & $0.1 \%$ & 1186 & $-0.7 \%$ & 1085 & $5.6 \%$ & 807 & $0.5 \%$ & 1160 \\
\hline
\end{tabular}


If we only compare the Relax-and-Fix methods, the method that minimizes delay (E) and with Overlapping (D) presents solutions that are, on average, 3\% higher than the values found with the MIP model. If we compare only the Fix-and-Optimize type methods, the best results are found using configuration partitions, particularly when the Relax-and-Fix methods that minimize backlogs $(\mathrm{H})$ or the Relax-and-Fix Overlapping methods $(\mathrm{G})$ are combined. It is a fact that by adding a solution improvement heuristic, such as Fix-and-Optimize, run times increase. However, runtimes still represent $1 / 3$ of the time consumed to solve the MIP model with CPLEX.

The overlapping strategies have more binary variables to be optimized at once in relation to the other strategies. Therefore, its processing time is considerably longer. Strategies that minimize backlogs are similar in principle to overlapping strategies in order to increase the number of integer variables not fixed to correct decisions fixed in previous iterations. Thus, by correcting badly fixed variables, both the strategies of overlapping and with minimization of the backlogs presented more effective results (relationship of computational time and quality of solution).

\section{CONCLUSIONS}

In this paper, we study the lotsizing and scheduling problem with process configuration selection. We propose a general mathematical model and solution methods based on mathematical programming: the MIP-heuristics. The literature presents several applied studies of this problem considering the various specificities of the real problems. However, general mathematical modeling is still rare and solution methods are specific to the problem or adapted directly from the problem without configuration selection. The proposed mathematical model for the lotsizing and sequencing problem comprises the selection of which configurations are used for the item production. This problem is common in process industries, for example in furniture manufacturing, molded pulp packaging and electrofused grain industries, which were used as references in this study.

Several MIP-heuristic strategies and combinations are proposed and compared using computational test results. Three sets of instances based on data from the furniture, molded pulp packaging and electro melted grain industries literature were used. The best strategy is to use the combination of MIP-heuristics Fix-and-Optimize with configuration partitions that use Relax-and-Fix, which minimizes backlogs. They present better results than the resolution of the mathematical model using CPLEX and in one third of the execution time. In general, the proposed model, as it stands or with some adaptations, has the potential to adequately represent the production planning environment of these and other process industries in practice. The Fix-and-Optimize heuristics with configuration partitions that use Relax-and-Fix that minimize backlogs is a good candidate to be used in practice to solve the problem.

An interesting perspective for future research would be to investigate other formulations such as CLSD (Capacitated Lotsizing Problem with sequence-dependent setups), valid inequalities for formulations and other more refined methods to solve larger instances of the problem, e.g., hybrid methods combining exact methods with metaheuristics. An exact method with the potential to 
solve this problem more effectively would be to adapt the algorithm Branch-and-Check using cuts based on the Benders logic explored in Martínez et al. (2019). The model and solution methods presented presume that all process configurations are known a priori. In cases where this is not reasonable, another interesting perspective for future research would be to reformulate the model. The possible configurations of these processes can be implicitly described in the model. Or, alternatively, developing solution methods with column generation procedures to implicitly determine the best process configurations in each problem. This generation will depend largely on the specific characteristics of the process and equipment involved and could be done through more sophisticated methods based on Dantzig-Wolfe decomposition with column generation and Branch-and-Price methods.

Other interesting future research would be to extend the model and solution methods to consider more general problem situations, for example, with multiple production lines in parallel (multimachines) and with multiple production stages (multi-level). Moreover, developing approaches to consider uncertainties in problem parameters, based on stochastic programming methods and robust optimization, for example. In some cases, companies have difficulties in accurately estimating the economic loss due to lack or backlogs in meeting demand. In these cases, the proposal of bi-objective approaches, considering the trade-off between the backlogs in meeting demand and the costs of product inventories and configuration changes, could be useful to support production planning. Finally, it would be interesting to better evaluate the impact of the practical implementation of the proposed solution approaches to the lotsizing and scheduling problem with process configuration selection in real situations of these and other process industries.

\section{ACKNOWLEDGEMENTS}

This study was financed in part by the Coordenação de Aperfeiçoamento de Pessoal de Nível Superior - Brasil (CAPES) - Finance Code 001. We would also like to thank CNPq and FAPESP (2016/01860-1).

\section{References}

[1] Absi N \& VAn den Heuvel W. 2019. Worst case analysis of Relax and Fix heuristics for lot-sizing problems. European Journal of Operational Research, 279: 449-458.

[2] Alem D \& Morabito R. 2013. Risk-averse two-stage stochastic programs in furniture plants. OR spectrum, 35: 773-806.

[3] Alem DJ, Munari PA, Arenales MN \& Ferreira PAV. 2010. On the cutting stock problem under stochastic demand. Annals of Operations Research, 179: 169-186.

[4] Almada-Lobo B, Clark A, Guimarães L, Figueira G \& Amorim P. 2015. Industrial insights into lot sizing and scheduling modeling. Pesquisa Operacional, 35 : 439-464. 
[5] Baldo TA, Santos MO, Almada-Lobo B \& Morabito R. 2014. An optimization approach for the lot sizing and scheduling problem in the brewery industry. Computers \& Industrial Engineering, 72: 58 - 71.

[6] Boonmee A \& Sethanan K. 2016. A GLNPSO for multi-level capacitated lotsizing and scheduling problem in the poultry industry. European Journal of Operational Research, 250: 652-665.

[7] Camargo VC, Toledo FM \& Almada-Lobo B. 2014. HOPS-Hamming-Oriented Partition Search for production planning in the spinning industry. European Journal of Operational Research, 234: 266-277.

[8] Chunpeng L \& GANG R. 2009. A strategy for the integration of production planning and scheduling in refineries under uncertainty. Chinese Journal of Chemical Engineering, 17: 113-127.

[9] Claassen G, Gerdessen J, Hendrix EM \& van der Vorst JG. 2016. On production planning and scheduling in food processing industry: Modelling non-triangular setups andproduct decay. Computers \& Operations Research, 76: 147-154.

[10] Clark A, Almada-Lobo B \& Almeder C. 2011. Editorial: Lot Sizing and Scheduling, Industrial Extensions and Research Opportunities, Special Issue on Lot Sizing and Scheduling. International Journal of Production Research, 49: 2457-2461.

[11] Clark AR, Morabito R \& Toso EAV. 2010. Production setup-sequencing and lotsizing at an animal nutrition plant through atsp subtour elimination and patching. Journal of Scheduling, 13: 111-121.

[12] Copil K, Wörbelauer M, Meyr H \& Tempelmeier H. 2017. Simultaneous lotsizing and scheduling problems: a classification and review of models. OR spectrum, 39: $1-64$.

[13] de Araujo SA, Arenales MN \& Clark AR. 2008. Lot sizing and furnace scheduling in small foundries. Computers \& Operations Research, 35: 916-932.

[14] Dillenberger C, Escudero LF, Wollensak A \& Zhang W. 1994. On practical resource allocation for production planning and scheduling with period overlapping setups. European Journal of Operational Research, 75: 275-286.

[15] dos Santos Diz GS, Hamacher S \& Oliveira F. 2019. A robust optimization model for the maritime inventory routing problem. Flexible Services and Manufacturing Journal, 31: 675-701.

[16] DreXl A \& Kimms A. 1997. Lot sizing and scheduling-survey and extensions. European Journal of Operational Research, 99: 221-235. 
[17] FAChini RF, Esposto KF \& CAMARgo VCB. 2018. A framework for development of advanced planning and scheduling (APS) systems in glass container industry. Journal of Manufacturing Technology Management, .

[18] Ferreira D, Clark AR, Almada-Lobo B \& Morabito R. 2012. Single-stage formulations for synchronised two-stage lot sizing and scheduling in soft drink production. International Journal of Production Economics, 136: 255 - 265.

[19] Ferreira D, Morabito R \& Rangel S. 2008. Um modelo de otimização inteira mista e heurísticas relax and fix para a programação da produção de fábricas de refrigerantes de pequeno porte. Produção, 18: 76-88.

[20] Ferreira D, Morabito R \& Rangel S. 2010. Relax and fix heuristics to solve onestage one-machine lot-scheduling models for small-scale soft drink plants. Computers \& Operations Research, 37: 684-691.

[21] Fiorotto DJ, JAns R \& De Araujo SA. 2018. Process flexibility and the chaining principle in lot sizing problems. International Journal of Production Economics, 204: 244-263.

[22] Fleischmann B \& Meyr H. 1997. The general lotsizing and scheduling problem. Operations-Research-Spektrum, 19: 11-21.

[23] Fransoo JC \& RUTTEN WG. 1994. A typology of production control situations in process industries. International Journal of Operations \& Production Management, 14: $47-57$.

[24] Furlan M, Almada-Lobo B, Santos M \& Morabito R. 2015. Unequal individual genetic algorithm with intelligent diversification for the lot-scheduling problem in integrated mills using multiple-paper machines. Computers \& Operations Research, 59: $33-50$.

[25] Furtado MgS, Camargo VC \& Toledo FM. 2019. The production planning problem of orders in small foundries. RAIRO-Operations Research, 53: 1551-1561.

[26] Gaudreault J, Frayret JM, Rousseau A \& D’ Amours S. 2011. Combined planning and scheduling in a divergent production system with co-production: A case study in the lumber industry. Computers \& Operations Research, 38: 1238-1250.

[27] Göthe-Lundgren M, Lundgren JT \& Persson JA. 2002. An optimization model for refinery production scheduling. International Journal of Production Economics, 78: $255-270$.

[28] Gramani M, França P \& Arenales M. 2009. A Lagrangian relaxation approach to a coupled lot-sizing and cutting stock problem. International Journal of Production Economics, 119: 219-227. 
[29] Helber S \& Sahling F. 2010. A fix-and-optimize approach for the multi-level capacitated lot sizing problem. International Journal of Production Economics, 123: $247-256$.

[30] Jans R \& Degraeve Z. 2008. Modeling industrial lot sizing problems: a review. International Journal of Production Research, 46: 1619-1643.

[31] JOHnson LA \& MONTGOMERY DC. 1974. Operations research in production planning, scheduling, and inventory control. vol. 6. Wiley New York.

[32] Karimi B, Ghomi SF \& WiLson J. 2003. The capacitated lot sizing problem: a review of models and algorithms. Omega, 31: $365-378$.

[33] Kopanos GM \& Puiguaner L. 2019. Solving Large-Scale Production Scheduling and Planning in the Process Industries. Springer.

[34] Leao AA, Furlan MM \& Toledo FM. 2017. Decomposition methods for the lotsizing and cutting-stock problems in paper industries. Applied Mathematical Modelling, 48: $250-268$.

[35] LU L \& QI X. 2011. Dynamic lot sizing for multiple products with a new joint replenishment model. European Journal of Operational Research, 212: 74-80.

[36] LuChe J \& Morabito R. 2005. Otimização na programação da produção de grãos eletrofundidos: Um estudo de caso. Gestão \& Produção, 12: 135-149.

[37] Luche JRD, Morabito R \& Pureza V. 2009. Combining process selection and lot sizing models for production scheduling of electrofused grains. Asia-Pacific Journal of Operational Research, 26: 421-443.

[38] Maes J \& Wassenhove LV. 1988. Multi-Item Single-Level Capacitated Dynamic LotSizing Heuristics: A General Review. Journal of the Operational Research Society, 39: 991-1004.

[39] Martínez KP, Adulyasak Y, Jans R, Morabito R \& Toso EAV. 2019. An exact optimization approach for an integrated process configuration, lot-sizing, and scheduling problem. Computers \& Operations Research, 103: 310-323.

[40] Martínez KP, Morabito R \& Toso EAV. 2018. A coupled process configuration, lot-sizing and scheduling model for production planning in the molded pulp industry. International Journal of Production Economics, 204: 227-243.

[41] Martínez KY, Toso EA \& Morabito R. 2016. Production planning in the molded pulp packaging industry. Computers \& Industrial Engineering, 98: 554-566.

[42] Melega GM, de Araujo SA \& Jans R. 2018. Classification and literature review of integrated lot-sizing and cutting stock problems. European Journal of Operational Research, 271: 1 - 19. 
[43] NONÅS SL \& THORSTENSON A. 2008. Solving a combined cutting-stock and lot-sizing problem with a column generating procedure. Computers \& Operations Research, 35 : 3371-3392.

[44] Persson JA, Göthe-Lundgren M, Lundgren JT \& Gendron B. 2004. A tabu search heuristic for scheduling the production processes at an oil refinery. International Journal of Production Research, 42: 445-471.

[45] Pochet Y \& Wolsey LA. 2006. Production planning by mixed integer programming. Springer Science \& Business Media.

[46] Poltroniere SC, Poldi KC, Toledo FMB \& Arenales MN. 2008. A coupling cutting stock-lot sizing problem in the paper industry. Annals of Operations Research, 157: $91-104$.

[47] SAhinidis N \& GRossmann IE. 1992. Reformulation of the multiperiod MILP model for capacity expansion of chemical processes. Operations Research, 40: S127-S144.

[48] Sahling F, Buschkühl L, Tempelmeier H \& Helber S. 2009. Solving a multi-level capacitated lot sizing problem with multi-period setup carry-over via a fix-and-optimize heuristic. Computers \& Operations Research, 36: 2546-2553.

[49] SeEanner F \& Meyr H. 2013. Multi-stage simultaneous lot-sizing and scheduling for flow line production. OR spectrum, pp. 1-41.

[50] Shi L, JiAng Y, WANG L \& HUANG D. 2014. Refinery production scheduling involving operational transitions of mode switching under predictive control system. Industrial \& Engineering Chemistry Research, 53: 8155-8170.

[51] Soler WA, Poldi KC \& SAntos MO. 2019. Capacitated lot sizing and scheduling with order acceptance and delivery time windows: mathematical model and a MIP-based heuristic. Pesquisa Operacional, 39: 471-496.

[52] Tempelmeier H \& Copil K. 2016. Capacitated lot sizing with parallel machines, sequence-dependent setups, and a common setup operator. OR spectrum, 38: 819-847.

[53] Toledo CFM, da Silva Arantes M, Hossomi MYB, França PM \& AKarTUNALI K. 2015. A relax-and-fix with fix-and-optimize heuristic applied to multi-level lot-sizing problems. Journal of heuristics, 21: 687-717.

[54] Toledo CFM, França PM, Morabito R \& Kimms A. 2009. Multi-population genetic algorithm to solve the synchronized and integrated two-level lot sizing and scheduling problem. International Journal of Production Research, 47: 3097-3119.

[55] Toscano A, Ferreira D \& Morabito R. 2019. A decomposition heuristic to solve the two-stage lot sizing and scheduling problem with temporal cleaning. Flexible Services and Manufacturing Journal, 31: 142-173. 
[56] Toscano A, Ferreira D \& Morabito R. 2020. Formulation and MiP-heuristics for the lot sizing and scheduling problem with temporal cleanings. Computers \& Chemical Engineering, 142: 107038.

[57] Toso EA, Morabito R \& Clark AR. 2009. Lot sizing and sequencing optimisation at an animal-feed plant. Computers \& Industrial Engineering, 57: 813 - 821.

[58] Wolsey LA. 1997. MIP modelling of changeovers in production planning and scheduling problems. European Journal of Operational Research, 99: 154-165.

\section{How to cite}

Villas Boas Be, Camargo VCB and Morabito R. 2021. Modeling and MiP-heuristics for the general lotsizing and scheduling problem with process configuration selection. Pesquisa Operacional, 41 (spe): e200000. doi: 10.1590/0101-7438.2021.041s1.00200000. 